\title{
Spinal Cord Lymphoma
}

National Cancer Institute

\section{Source}

National Cancer Institute. Spinal Cord Lymphoma. NCI Thesaurus. Code C5157.

A non-Hodgkin or Hodgkin lymphoma that arises in the spinal cord as a primary lesion. 